\title{
Evaluation of Infection Prevention and Control Programmes (IPC), and Assessment Tools for IPC-Programmes at MOH-Health Facilities in Saudi Arabia
}

\author{
Abdullah M. Assiri' ${ }^{1}$ Abdul Jamil Choudhry², Suhair S. Alsaleh2, Khalid H. Alanazi2, \\ Suha S. Alsaleh ${ }^{3}$ \\ ${ }^{1}$ Department of Medicine, King Fahad Medical City, Riyadh, KSA \\ ${ }^{2}$ Ministry of Health, Riyadh, KSA \\ ${ }^{3}$ Imam Abdulrahman bin Faisal Hospital, Dammam-National Guard Health Affairs, Dammam, KSA \\ Email: ${ }^{*}$ suhair.research@yahoo.com
}

Received 22 April 2014; revised 23 May 2014; accepted 4 June 2014

Copyright (C) 2014 by authors and Scientific Research Publishing Inc.

This work is licensed under the Creative Commons Attribution International License (CC BY).

http://creativecommons.org/licenses/by/4.0/

(c) (i) Open Access

\section{Abstract}

Infection Prevention and Control is a Quality Standard and is crucial in all health care facilities. Many hospitals remain deficient in trained infection control professionals (ICPs), and now there is an acute awareness of the need to correct this shortfall. The objectives of the study were to describe the current status of ICP programs at ministry of health $(\mathrm{MOH})$ and to evaluate the current status of infection prevention and control programs at health care facilities in kingdom of Saudi Arabia. A cross sectional interview and a self assessment study were conducted on infection prevention and control (IPC) program in Saudi Arabia. All the MOH hospital in all regions was randomly chosen to the study setting. The selection of facilities was done at random with a clear intention to include twenty regions. A random sample was taken from these hospitals with sample size 56 (55.4\%), by Multi stage random sampling technique. Results showed that the total facility in all over the kingdom was $\mathbf{5 1 . 4 \%}$ where central area covered the facility score $58.2 \%$, followed by western area $(54.8 \%)$, south (53.7\%), east $(46.3 \%)$, and lastly with $(45.8 \%)$ north area. Survey revealed that the infrastructure for infection control program in Saudi Arabian hospitals remained underdeveloped. There were defects in the identified components of effective infection control programs.

\section{Keywords}

Infection Prevention Control, Assessment Tools, Health Facility, Saudi Arabia

\footnotetext{
${ }^{*}$ Corresponding author.
}

How to cite this paper: Assiri, A.M., et al. (2014) Evaluation of Infection Prevention and Control Programmes (IPC), and Assessment Tools for IPC-Programmes at MOH-Health Facilities in Saudi Arabia. Open Journal of Nursing, 4, 483-492. 


\section{Introduction}

Infection Prevention and Control is a Quality Standard and is essential in all health care facilities for the wellbeing and safety of patients, staff, visitors and all who come within the scope of activities. Each healthcare facility designs and establishes a coordinated program to identify and reduce the risk of infection acquisition and transmission among patients, staff, and visitors [1]. Infectious diseases remain a leading cause of morbidity and mortality in the kingdom, but most of the diseases are extremely preventable or treatable. The ministry of health (MOH) annual report (1996) lists chickenpox, amebic dysentery, and brucellosis as the 3 most common communicable diseases in Saudi Arabia with patients suffering from it [2].

IPC programs have been shown to be both clinically and cost-effective [3]-[6] providing important cost savings in terms of fewer Health care-associated infections (HAIs), reduced length of hospital stay, less antimicrobial resistance and decreased costs of treatment for infections [7]-[9]. The Public Health Agency of Canada (PHAC) has outlined the human and economic perspectives of HAIs, demonstrating the rationale and need for appropriate and adequate resources for IPC programs.

(HAI) are an important public health problem because they occur frequently, cause morbidity and mortality and represent a significant burden among patients, health-care workers and health systems. HAI occur worldwide and affect all countries, irrespective of their degree of development. The most common types of HAI include infections of surgical wounds, the blood stream, the urinary tract and the lower respiratory tract. In some settings, gastrointestinal infections are also common. Infection rates are higher among patients with increased susceptibility because of their age, severity of the underlying disease, use of invasive devices and procedures, or conditions that impair the immune system [9].

The Kingdom of Saudi Arabia is located in the Middle East, bordering the Persian Gulf and the Red Sea, north of Yemen and has estimated population of 26,534,504 (July 2012 est.) including 5,576,076 non-nationals [10]. Currently the $\mathrm{MOH}$ is the major government provider and financer of health care services in Saudi Arabia, with a total of 249 hospitals (33,277 beds) and 2037 primary health care (PHC) centers [11]. These services comprise $26.0 \%$ of the total health services in Saudi Arabia [11].

The other government bodies include referral hospitals (e.g. King Faisal Specialist Hospital and Research Centre), security forces medical services, army forces medical services National Guard health affairs, Ministry of Higher Education hospitals (teaching hospitals), ARAMCO hospitals, Royal Commission for Jubail and Yanbu health services, school health units of the Ministry of Education and the Red Crescent Society. With the exception of referral hospitals, Red Crescent Society and the teaching hospitals, each of these agencies provides services to a defined population, usually employees and their dependants. Additionally, all of them provide health services to all residents during crises and emergencies [12]. Jointly, the government bodies operate 39 hospitals with a capacity of 10,822 beds [11]. The private sector also contributes to the delivery of health care services, especially in cities and large towns, with a total of 125 hospitals (11,833 beds) and 2218 dispensaries and clinics [11]. The nations of the GCC states, including Saudi Arabia, are now facing the tremendous impact of hospital acquired infection [13].

Nosocomial infection is a medical and economic problem of global importance. In 1992 in the United States, hospital-acquired infections complicated $6 \%$ of all hospitalizations, at a health care cost of US $\$ 4.5$ billion [14]. With use of conservative assumptions, a one-third reduction in incidence of nosocomial infections in Asia and Africa could result in monetary savings of US \$230 billion to \$2 to \$3 trillion annually [15]. In Kuwait, nosocomial infections in the 1970 s occurred in $5.1 \%$ of all inpatients, costing its national health care system US $\$ 267,000$ daily [15] [16]. An urban hospital in the Kingdom of Saudi Arabia reports a 2.2\% nosocomial infection rate 16 and other reports have documented that nosocomial infections are a problem elsewhere in the kingdom [17]-[20].

Many hospitals remain deficient in trained infection control professionals (ICPs), and now there is an acute awareness of the need to correct this shortfall. Human resources for the discipline of infectious disease remain inadequate in Saudi Arabia. The Saudi Council for Health Specialties, established in 1990, began developing training programs in internal medicine and pediatrics, among other core specialties. The kingdom now has a large number of nationally trained Saudi internists and pediatricians. Currently the Saudi Council for Health Specialties is establishing subspecialty training in infectious disease to fulfill vast domestic demands [21]. Infection prevention and control in the kingdom are new and growing disciplines. A successful infection control program relies on several vital and interdigitating components: adequately trained manpower services; responsive 
hospital based infrastructures, and nationwide arenas of professional communication.

Saudi Arabia has rapidly activated each of these components to build a vital and current infection control community of high standards. The MOH provides training courses in infection control for allied health professionals. In addition, the MOH now offers field epidemiology training. After thorough searching of databases, there are no published studies addressing in Assessment of infection prevention and control programs in Saudi Arabia. To our knowledge nobody evaluate the current status of infection prevention and control programs at health care facilities in kingdom of Saudi Arabia, therefore, the main purpose of this study is to describe the current status of ICP programs at $\mathrm{MOH}$ health facilities. Additionally, the study was designed to evaluate the current status of infection prevention and control programs at health care facilities in kingdom of Saudi Arabia.

\section{Methods}

A cross sectional interview based study was conducted in Kingdom of Saudi Arabia (KSA) over a period of 4 months from January through April 2013. All the MOH hospital (249) in all regions according to their geographical distribution (Eastern, Northern, Southern, Western and Central) of Saudi Arabia was included in the study setting. Data collection was carried out using infection prevention and control (IPC) core components assessment tools (IPCAT). The tools were designed and developed from a review of the literature relating to ICP programmes [22]. The survey components were pre-tested by a health care professional with an extensive experience in ICP programmes. A draft of the tools was piloted on a convenience of some practicing health care professionals to check for readability, understanding, tools design and the length of the components. Based on the result of this pilot study the tools were used with little modifications and the final component was sent to the participants through handling by face to face, mail or E-mail.

IPCAT tools consists of eight core components of IPC programmes which are essential in strengthening capacity for the prevention of health care-associated infections (HAI) and in preparing an effective response to emergencies involving communicable diseases. The tools were designed to provide a general overview on the status of HAI prevention and control activities. Each component is divided into several sections with essential elements (indicators) of IPC programmes. Every element is a true/false statement. " 1 ” is assigned if the element exists (implemented, introduced etc.), and " 0 " means the statement is false (i.e. the element does not exist). A stratified random sample size of 56 (55.4\%) was taken by Multi stage random sampling technique. The first stage sampling units were the twenty regions of KSA to be included. The second stage sampling units was to include only selective number of hospitals for the assessment. Hospital capacity should be minimum 100 beds, and should have acute care unit. Mentally health hospitals were excluded from the study. So out of 249 hospitals, only 101 hospitals fulfill the criteria. From each region, a random sample was taken.

The selection of facilities was done at random with a clear intention to include different regions of Saudi Arabia, North area comprises of five different regions Tabuk Region (Tb) Hail Region (Hi) North boarder Region (Nb) Aljouf Region (Jf) Alqurayyat Region (Qr) with 10 numbers in hospitals , South area includes Jazan Region (Jz), Albaha Region (Ba) Najran Region (Nj) Bisha Region (Bi) Aseer Region (As) with total of 14 different hospitals , East area mainly covers , Eastern Province Region (Ep) which includes Dammam Central Hospital, Qatif Central Hospital, Alkhafgi Central Hospital, AlAhsa Region (Ah), and Hafr Al-Batin Region (Hb). However, Central area mainly covers the capital city of Saudi Arabia (i.e.,) Riyadh Region (Ry), Al-Qassim Region (Qa) with 13 number of hospitals. West area covers the main cities Makka, Al-madina, Jeddah, Taif and Alqunfutha (Qn) Regions with 13 number of hospital. The list of hospitals participated in survey was illustrated in Table 1. The data were entered directly onto the worksheets, Evaluation scores are calculated automatically for every subcomponent and every core component in total. A negative answer automatically highlights the element in red for easy reference. There is also a field for comments, a field with verifiers, and a field with definitions and examples.

\section{Results}

Results showed that the total facility level in all over the kingdom was advanced or intermediate with score of (51.4\%). Data regarding on total facility score of all health care facilities were illustrated in Figure 1 where central area covered the highest facility score $58.2 \%$, followed by western area (54.8\%), south area (53.7\%), east area (46.3\%), and lastly with (45.8\%) north area. Figure 2 illustrated the data on ICP components in national level. The component organization of IPC program, score was found to be (54.5\%). Study showed that 
Table 1. The complete list of the hospitals involved in survey.

\begin{tabular}{|c|c|c|c|c|}
\hline Area & Regions & Name of the hospital & No of Beds & Code \\
\hline \multirow[t]{14}{*}{ South area } & Jazan Region (Jz) & King Fahd Hospital & 450 & Jz001 \\
\hline & & Abu Areesh General Hospital & 125 & Jz002 \\
\hline & & Sabya General Hospital & 150 & Jz003 \\
\hline & Al-baha Region $(\mathrm{Ba})$ & King Fahd Hospital & 320 & $\mathrm{Ba} 001$ \\
\hline & & Baljurshi General Hospital & 150 & $\mathrm{Ba} 002$ \\
\hline & Najran Region (Nj) & King Khaled Hospital & 300 & Nj001 \\
\hline & & Maternity and Child Hospital & 200 & Nj002 \\
\hline & Bisha Region (Bi) & King Abdullah Hospital & 360 & $\mathrm{Bi} 001$ \\
\hline & Aseer Region (As) & Aseer Central Hospital & 500 & As001 \\
\hline & & Maternity and Child Hospital in K.M. & 100 & As002 \\
\hline & & Sarat Obaida Hospital & 110 & As003 \\
\hline & & Balsamar Hospital & 100 & As004 \\
\hline & & MahailAssir Hospital & 170 & As005 \\
\hline & & Regal Almaa Hospital & 100 & As006 \\
\hline \multirow[t]{6}{*}{ East area } & Eastern Province Region (Ep) & Dammam Central Hospital & 430 & Ep001 \\
\hline & & Qatif Central Hospital & 235 & Ep002 \\
\hline & & Alkhaafgi Central Hospital & 100 & Ep003 \\
\hline & AlAhsa Region (Ah) & King Fahd Hospital & 575 & Ah001 \\
\hline & & Maternity and Child Hospital & 450 & Ah002 \\
\hline & Hafr Al-Batin Region (Hb) & King Khaled General Hospital & 300 & Hb001 \\
\hline \multirow[t]{13}{*}{ Central area } & Riyadh Region (Ry) & King Saud Medical City & 1094 & Ry001 \\
\hline & & Prince Salman Hospital & 264 & Ry002 \\
\hline & & Yamama Hospital & 310 & Ry003 \\
\hline & & King Khalid (Kharj) Hospital & 300 & Ry004 \\
\hline & & Dwadmi General Hospital & 200 & Ry005 \\
\hline & & Shaqra General Hospital & 150 & Ry006 \\
\hline & & Afif General Hospital & 130 & Ry007 \\
\hline & & Aflaj General Hospital & 120 & Ry008 \\
\hline & & Hotat Bin Tamim Hospital & 100 & Ry009 \\
\hline & AlQassim Region (Qa) & King Fahd Hospital & 380 & Qa001 \\
\hline & & Maternity and Child Hospital & 245 & Qa002 \\
\hline & & Alrus General Hospital & 250 & Qa003 \\
\hline & & AlMuthnab General Hospital & 130 & Qa004 \\
\hline \multirow[t]{9}{*}{ West area } & Makkah Region (Mk) & Alnoor Specialist Hospital & 500 & Mk001 \\
\hline & & King Abdulaziz Hospital & 300 & Mk002 \\
\hline & & Maternity and Child Hospital & 210 & Mk003 \\
\hline & Jeddah Region (Jd) & King Fahd Hospital & 610 & Jd001 \\
\hline & & Maternity and Child Aziziah Hospital & 125 & Jd002 \\
\hline & & Althaqr Hospital & 100 & Jd003 \\
\hline & & Rabig General Hospital & 120 & Jd004 \\
\hline & Taif Region (Tf) & King Abdulaziz Hospital & 100 & Tf001 \\
\hline & & Pediatrics Hospital & 100 & Tf002 \\
\hline
\end{tabular}




\section{Continued}

\begin{tabular}{|c|c|c|c|c|}
\hline & Madina-Munnawara Region & King Khalid Eye Specialist Hospital & 405 & Md001 \\
\hline & & Ohod General Hospital & 250 & Md002 \\
\hline & & Yanbu General Hospital & 300 & Md003 \\
\hline & Al-Qunfudah Region (Qn) & AlQunfudah General Hospital & 200 & Qn001 \\
\hline \multirow[t]{9}{*}{ North area } & Tabuk Region (Tb) & King Khalid Hospital & 270 & Tb001 \\
\hline & & Maternity and Child Hospital & 100 & Tb002 \\
\hline & & Al-Wajh Hospital & 200 & Tb003 \\
\hline & Hail Region (Hl) & King Khaled Hospital & 288 & Hi001 \\
\hline & & Maternity and Child Hospital & 125 & $\mathrm{Hi002}$ \\
\hline & AlJouf Region (Jf) & Prince A. Al-Sudairy Hospital & 180 & Jf001 \\
\hline & & DomatAljundal Hospital & 130 & Jf002 \\
\hline & Alqurayyat (Qr) & Qurayyat General Hospital & 240 & Qr001 \\
\hline & North Borders Region (Nb) & Arar General Hospital & 300 & Nb001 \\
\hline
\end{tabular}

\section{Total Facility Score}

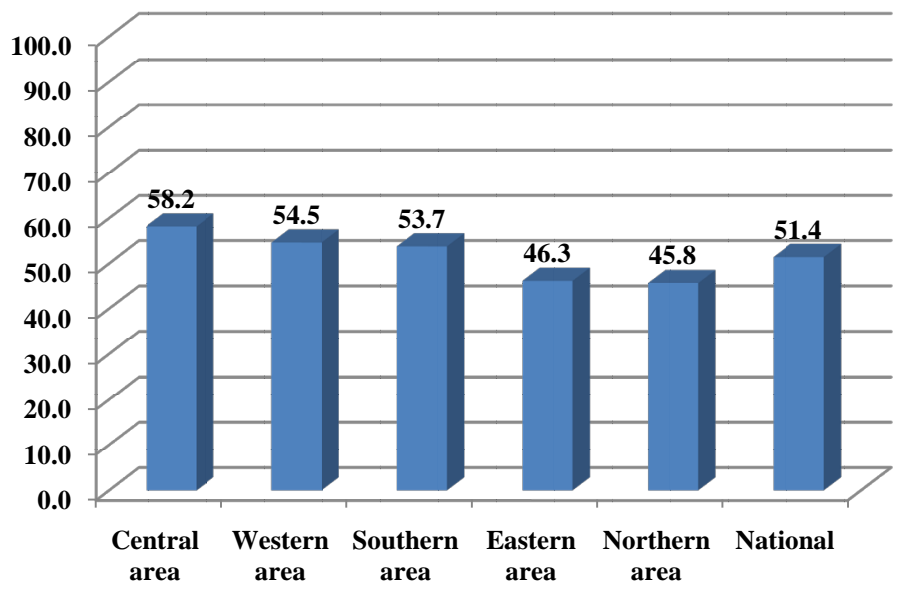

Figure 1. Showing the total facility score of ICP components in different regions.

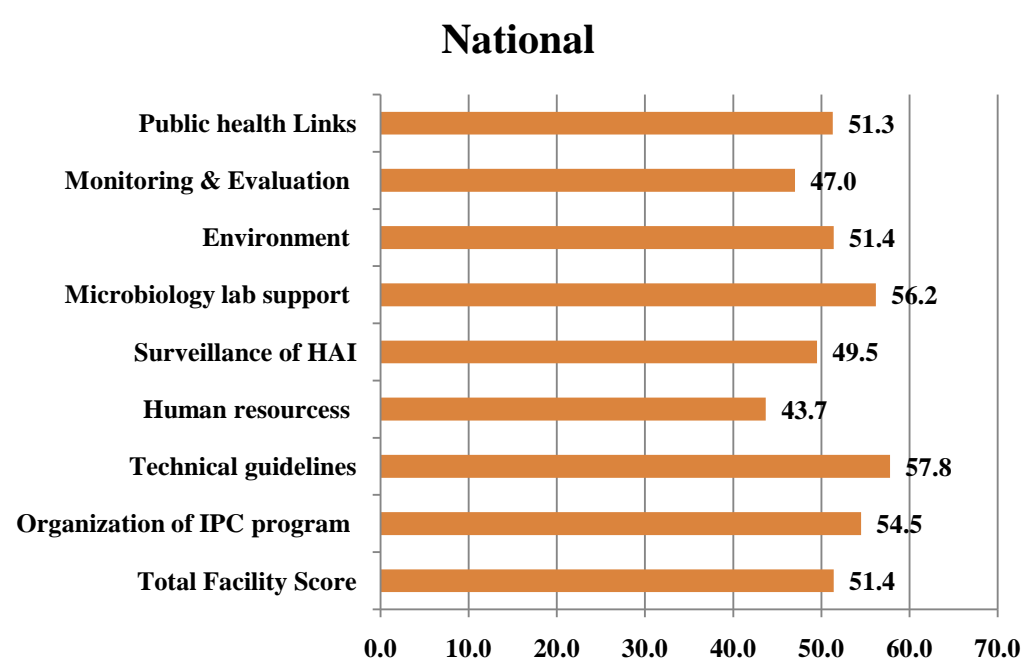

Figure 2. Showing the total facility score of ICP components in national level. 
technical guidelines represented $57.8 \%$ in total of all the five areas, in national level. Survey results showed that scores on human resources were $43.7 \%$. However score on Surveillance of HAI was found to be (49.5\%), almost all infection control programs had access to microbiology laboratory services with score of (56.2\%) in health care facilities in the kingdom.

Survey results shown that environment of IPC program were found to be (51.4\%). According to our assessment unlike other ICP components, Monitoring \& Evaluation was found to be (47\%) in national level, Finally, Survey results shown that links with public and other health services were found to be (51.3\%) in all over kingdom.

The facility score for IPC components in different areas of hospitals at Saudi Arabia was shown in Table 2. Organization of IPC program for central area having (61.7\%), western and southern area $(57.1 \%$, 55.6\%) followed by eastern area (50.1\%), of the facility northern area having (50.6\%). Central area possessing intermediate score of (64.9\%) on technical guidelines, additionally west area (60.8\%) and with little differences Southern area (57.3\%) followed by and north and east area respectively $(53.6 \%, 53.1 \%)$. The score on human resources for central area was (46.7\%), western (46\%), south (45\%) east $(42.1 \%)$ and lastly with north area (39.6\%). this results suggested that human resources are not well implemented in all over the kingdom. Surveillance of HAI was (55.5\%) in central area, followed by western area (52.8\%), south area (52.3\%), east (44.6\%) and finally (43.9\%) north area. Results regarding microbiology laboratory support for central area were $63.7 \%$, western area (60.5\%), south (57.8\%), and east and north area possessing (52.8\%, 49.3\%) respectively. However, environment of the ICP program plays important role in all health care facilities, central area having score of (59.8\%) for environment followed by western (57.4\%), south (53.4\%) east (42\%) and north was (45.8\%). The component Monitoring \& Evaluation level in central area was (54.4\%), western area (50\%), southern area (50.6\%) east and north area $(40.3 \%, 40 \%)$ respectively. The central area having highest levels to maintain links with public and other health services with a score of (59\%) followed by western and south (54.1\%, 57.8\%), north (44.3\%) and lastly east area with a score of (42.6\%) respectively.

The percentage of level of health care facilities in all the 20 regions of Saudi Arabian hospitals was depicted in Table 3.

\section{Discussion}

This study evaluated the assessments tools for infection prevention and control programs in different regions of Saudi Arabia. Prior to designing a strategy for implementation of IPC program, the opinions of the health care professionals should be explored, since these opinions influence the implementation of IPC program either directly or indirectly by creating unfavorable environment of lack of support from peers and seniors.

It is clear from this result that the total health care facility in Saudi Arabia is found to be $51.4 \%$. This result suggests the manpower needs evolved in concert with the kingdom's extraordinary growth. Many hospitals remain deficient in trained infection control professionals (ICPs), and now there is an acute awareness of the need to correct this shortfall. Results show that Human resources for the discipline of infection control program (IPC) remain inadequate (43.7\%) in Saudi Arabia. These results are similar to other studies [13].

Several studies have outlined that human resources require effective IPC programs in a variety of settings [23] [24]. There is evidence that all health care facilities must have IPC professionals (ICPs) and should have access to a trained IPC physician as well as administrative support staff appropriate to the IPC program. In addition to a trained ICP, there is evidence that establishing a relationship with IPC champions in clinical programs and departments aids the IPC team in carrying out their mandate [25]. Some studies [26] suggested that to improve human resources certain qualifications be met by professionals in IPC. ICPs must be a Certified in Infection Control from the Certification Board of Infection Control and Epidemiology (CBIC) when eligible, not only that, ICPs must pass a CHICA-Canada endorsed education program which comprises a minimum of 80 hours of instruction, and also ICPs must have a health sciences background with teaching, problem-solving, communication and analytical skills that will allow them to plan, implement and evaluate their programs.

However, the study results identified deficits in several components of effective IPC programs, in all over the kingdom, including training of IPC programs, ventilation facilities, use of antimicrobials, and staffing ratios. These results were comparable with a study where a Canadian survey of acute care hospitals identified deficits was staffing levels, surveillance activities and access to laboratories [27]. This lack of facilities in ICPs has been a severe limiting factor in the efficacy of infection control in Saudi Arabia [15]. To improve health care 
Table 2. Illustrating the major ICP components and their values in different areas of Saudi Arabia.

\begin{tabular}{ccccccc}
\hline ICP components & North area & East area & Central area & West area & South area & National level \\
\hline Organization of IPC program & $50.6 \%$ & $50.1 \%$ & $61.7 \%$ & $57.1 \%$ & $55.6 \%$ & $54.5 \%$ \\
Technical guidelines & $53.6 \%$ & $53.1 \%$ & $64.9 \%$ & $60.8 \%$ & $57.3 \%$ & $57.8 \%$ \\
Human resources & $39.6 \%$ & $42.1 \%$ & $46.7 \%$ & $46.0 \%$ & $45.0 \%$ & $43.7 \%$ \\
Surveillances of HAI & $43.9 \%$ & $44.6 \%$ & $55.5 \%$ & $52.8 \%$ & $52.3 \%$ & $49.5 \%$ \\
Microbiology lab support & $49.3 \%$ & $52.8 \%$ & $63.7 \%$ & $60.5 \%$ & $57.8 \%$ & $56.2 \%$ \\
Environment & $45.8 \%$ & $42.0 \%$ & $59.8 \%$ & $57.4 \%$ & $53.4 \%$ & $51.4 \%$ \\
Monitoring \& evaluation & $40.0 \%$ & $43.3 \%$ & $54.4 \%$ & $50.0 \%$ & $50.6 \%$ & $47.0 \%$ \\
Public health links & $44.3 \%$ & $42.6 \%$ & $59.0 \%$ & $54.1 \%$ & $57.8 \%$ & $51.3 \%$ \\
\hline
\end{tabular}

Table 3. Illustrating ICP tools and their percentage of level of health care facilities in all the 20 regions of Saudi Arabian hospitals.

\begin{tabular}{|c|c|c|c|c|c|c|c|c|}
\hline \multirow[b]{2}{*}{ Regions } & \multicolumn{8}{|c|}{ ICP components } \\
\hline & $\begin{array}{l}\text { Organization of } \\
\text { IPC program }\end{array}$ & $\begin{array}{l}\text { Technical } \\
\text { guidelines }\end{array}$ & $\begin{array}{l}\text { Human } \\
\text { resources }\end{array}$ & $\begin{array}{l}\text { Surveillance } \\
\text { of HAI }\end{array}$ & $\begin{array}{l}\text { Microbiology } \\
\text { lab support }\end{array}$ & Environment & $\begin{array}{c}\text { Monitoring \& } \\
\text { evaluation }\end{array}$ & $\begin{array}{l}\text { Public health } \\
\text { links }\end{array}$ \\
\hline Jazan & $46.0 \%$ & $58.7 \%$ & $43.0 \%$ & $47.7 \%$ & $47.7 \%$ & $55.0 \%$ & $53.3 \%$ & $60.7 \%$ \\
\hline Najran & $56.0 \%$ & $48.0 \%$ & $48.0 \%$ & $47.5 \%$ & $58.0 \%$ & $41.0 \%$ & $45.0 \%$ & $50.0 \%$ \\
\hline Bisha & $56.0 \%$ & $60.0 \%$ & $48.0 \%$ & $52.0 \%$ & $58.0 \%$ & $59.0 \%$ & $60.0 \%$ & $56.0 \%$ \\
\hline Al-baha & $59.5 \%$ & $66.0 \%$ & $45.5 \%$ & $56.5 \%$ & $58.0 \%$ & $56.0 \%$ & $50.0 \%$ & $66.0 \%$ \\
\hline Asir & $60.7 \%$ & $64.0 \%$ & $43.5 \%$ & $57.8 \%$ & $67.3 \%$ & $56.0 \%$ & $45.0 \%$ & $56.5 \%$ \\
\hline Al-Ahsa & $56.5 \%$ & $62.0 \%$ & $40.5 \%$ & $45.5 \%$ & $60.5 \%$ & $38.0 \%$ & $40.0 \%$ & $38.0 \%$ \\
\hline Eastern & $50.0 \%$ & $49.3 \%$ & $38.0 \%$ & $40.0 \%$ & $51.0 \%$ & $41.0 \%$ & $40.0 \%$ & $40.0 \%$ \\
\hline Al-Batin & $44.0 \%$ & $48.0 \%$ & $48.0 \%$ & $48.0 \%$ & $47.0 \%$ & $47.0 \%$ & $50.0 \%$ & $50.0 \%$ \\
\hline Riyadh & $65.2 \%$ & $68.8 \%$ & $50.4 \%$ & $60.0 \%$ & $67.3 \%$ & $57.7 \%$ & $58.9 \%$ & $61.3 \%$ \\
\hline Al Qasim & $58.2 \%$ & $61.0 \%$ & $43.0 \%$ & $51.0 \%$ & $60.2 \%$ & $62.0 \%$ & $50.0 \%$ & $56.7 \%$ \\
\hline Makkah & $58.3 \%$ & $60.0 \%$ & $46.3 \%$ & $54.0 \%$ & $65.3 \%$ & $59.0 \%$ & $50.0 \%$ & $56.3 \%$ \\
\hline Madina & $58.3 \%$ & $64.0 \%$ & $50.7 \%$ & $59.3 \%$ & $66.3 \%$ & $57.0 \%$ & $50.0 \%$ & $56.3 \%$ \\
\hline Jeddah & $66.0 \%$ & $66.0 \%$ & $51.0 \%$ & $51.0 \%$ & $63.0 \%$ & $59.0 \%$ & $60.0 \%$ & $58.0 \%$ \\
\hline Taif & $47.0 \%$ & $50.0 \%$ & $39.0 \%$ & $48.0 \%$ & $50.0 \%$ & $47.0 \%$ & $40.0 \%$ & $44.0 \%$ \\
\hline Qunfutha & $56.0 \%$ & $64.0 \%$ & $43.0 \%$ & $52.0 \%$ & $58.0 \%$ & $65.0 \%$ & $50.0 \%$ & $56.0 \%$ \\
\hline Tabuk & $50.0 \%$ & $56.0 \%$ & $43.0 \%$ & $48.0 \%$ & $54.7 \%$ & $47.0 \%$ & $40.0 \%$ & $42.0 \%$ \\
\hline Hail & $50.0 \%$ & $54.0 \%$ & $48.0 \%$ & $52.0 \%$ & $58.0 \%$ & $50.0 \%$ & $45.0 \%$ & $50.0 \%$ \\
\hline North & $50.0 \%$ & $58.0 \%$ & $43.0 \%$ & $45.5 \%$ & $50.0 \%$ & $50.0 \%$ & $45.0 \%$ & $50.0 \%$ \\
\hline AlJouf & $53.0 \%$ & $48.0 \%$ & $31.0 \%$ & $35.0 \%$ & $37.0 \%$ & $35.0 \%$ & $40.0 \%$ & $35.5 \%$ \\
\hline AlQryat & $50.0 \%$ & $52.0 \%$ & $33.0 \%$ & $39.0 \%$ & $47.0 \%$ & $47.0 \%$ & $30.0 \%$ & $85.8 \%$ \\
\hline
\end{tabular}

safety and cost-efficiencies in Saudi Arabia appropriately resourced IPC programs must be a standard of practice. While the final accountability rests with the administration of the organization, IPC programs that have the required expertise and resources will assist and support the organization to improve patient safety by protecting clients/patients/residents, health care providers, visitors and others from HAIs, with the added benefit of reducing costs to the health care system [4] [28].

However, the result found that the availability of the resources like budget and clean water facilities was good enough for all the regions and clean water facilities were found to be available in all over the kingdom. This brings the Saudi health system to gain its standards. Equally defining has been the lack of conformity among microbiologic support services in Saudi Arabia. Results showed that the microbiological lab support was found to be $56.2 \%$ in all over the kingdom. This suggests that laboratories are not monitored by a nationally standar- 
dized body nor do they all follow any one Western model, frustrating any hopes of nationally Imposed guidelines or standards and leading to further variations in clinical infection control medicine.

The results of the study revealed that the health facilities in central area in the kingdom were found to be $58.2 \%$ as slightly well, comparing to other areas in Saudi Arabia. This is because of the central area were utilizing developed methods, and Standard Precautions include hand hygiene, use of personal protective equipment (PPE) to avoid direct contact with patient's blood, body fluids, secretions and non-intact skin, prevention of needle stick/sharp injury and cleaning and disinfection of the environment and equipment for IPC programmes, and early reporting and analysis of IPC programs, comparing to other areas, of Saudi Arabia.

It is worth noting that total facility Score for IPC program in western area was found to be (54.8\%). This is because of the western region containing the two holy cities Mecca and Madina where millions of pilgrims come to visit for hajj and umrah. The epidemiologic pressures of the Hajj lack any Western equivalent, and with increasing globalization, air travel, and affluence [23], there was a chance of increase infection and limiting the area from infection control comparing to central area and other. Saudi Arabian infection control systems may not respond as rapidly to new information because there is a lack of standardization across the foundations of infection control. Timely upgrading of such an infection control system becomes difficult. These diversities in the foundations of infection control are Reflections of the varied health organizations in the Saudi community. Without doubt, a major contrasting factor is the maturity of infection.

Control as a Saudi discipline. Though admirably catching up in development, clinical and economic experience remains to be garnered. More important than cumulative experience is the ability for Saudi Arabia to perform outcomes research and monitoring of infection control policies to accelerate gains made in this field.

To develop a well established an infection control program appropriate infrastructure in each health care facility is needed. Without a viable infrastructure, infection control program cannot be implemented. All practitioners need appropriate resources. These resources include adequate office space and equipment; computerization; clinical microbiologic support services (including molecular typing capabilities); current, rapid-access multimedia information through internet portals; peer-reviewed journals; and certified training courses. These vital amenities are widely available in most large hospitals in the kingdom and are rapidly becoming standardized.

\section{Conclusion and Recommendations}

In conclusion, our survey revealed that the infrastructure for infection control program in Saudi Arabian hospitals remains underdeveloped. There were defects in the identified components of effective infection control programs. Greater investment in resources of IPC component is needed to meet recommended standards and thereby reduce morbidity, mortality, and expense associated with health care associated infections and other resistant pathogens. Additionally, all health care settings in Saudi Arabia must assess needs for developing, providing and evaluating an active, effective ICP program that meets the mandate and goal to decrease the risk of health careassociated infections and improve health care safety. Finally, more consideration to ICP issues should be addressed in health care settings' and continuous education program for health care workers to follow infection control precautions.

\section{Acknowledgements}

The authors thank the following individuals, including their staffs, for all their support, which was critical to the success of our research collaboration: Dr. Abdulla Assiri General Directorate of ICP-department in MOH in KSA for his great support and advice, Mr. Abdulla Al-mutairi, the Doctors and Nurses of all MOH-hospitals we visited in KSA.

\section{References}

[1] Gulf Cooperation Council (2009) Infection Prevention and Control Manual, National Guard Health Affairs. King Abdulaziz Medical City Riyadh.

[2] (1996) Ministry of Health Annual Report 1996, Kingdom of Saudi Arabia. Ministry of Health, Riyadh, 30.

[3] Haley, R.W., Morgan, W.M., Culver, D.H., White, J.W., Emori, T.G., Mosser, J., et al. (1985) Update from the SENIC project. Hospital Infection Control: Recent Progress and Opportunities under Prospective Payment. American Journal of Infection Control, 13, 97-108. http://dx.doi.org/10.1016/S0196-6553(85)80010-9 
[4] Stone, P.W., Larson, E. and Kawar, L.N. (2002) A Systematic Audit of Economic Evidence Linking Nosocomial Infections and Infection Control Interventions: 1990-2000. American Journal of Infection Control, 30, 145-152. http://dx.doi.org/10.1067/mic.2002.121099

[5] Wenzel, R.P. (1995) The Lowbury Lecture. The Economics of Nosocomial Infections. Journal of Hospital Infection, 31, 79-87. http://dx.doi.org/10.1016/0195-6701(95)90162-0

[6] Graves, N., Halton, K. and Lairson, D. (2007) Economics and Preventing Hospital-Acquired Infection: Broadening the Perspective. Infection Control and Hospital Epidemiology, 28, 178-184. http://dx.doi.org/10.1086/510787

[7] Haley, R.W., Culver, D.H., White, J.W., Morgan, W.M., Emori, T.G., Munn, V.P., et al. (1985) The Efficacy of Infection Surveillance and Control Programs in Preventing Nosocomial Infections in US Hospitals. American Journal of Epidemiology, 121, 182-205.

[8] Jodra, V.M., de los Terreros Soler, L.S., Pérez, C.D.-A., Requejo, C.M.S. and Farrás, N.P. (2006) Excess Length of Stay Attributable to Surgical Site Infection Following Hip Replacement: A Nested Case-Control Study. Infection Control and Hospital Epidemiology, 27, 1299-1303. http://dx.doi.org/10.1086/509828

[9] Ehrenkranz, N.J. (1986) The Efficacy of a Florida Hospital Consortium for Infection Control: 1975-1982. Infection Control, 7, 321-326.

[10] (2012) Saudi Arabia Demographic Profile 2012.

[11] (2009) Health Statistical Year Book. Ministry of Health, Riyadh.

[12] Mufti, M.H.S. (2000) Healthcare Development Strategies in the Kingdom of Saudi Arabia. Kluwer Academic/ Plenum, New York.

[13] Memish, Z.A. (2002) Infection Control in Saudi Arabia: Meeting the Challenge. American Journal of Infection Control, 30, 57-65.

[14] (1992) Centers for Diseases Control and Prevention. Public Health Forces: Surveillance, Prevention and Control of Nosocomial Infections. Morbidity and Mortality Weekly Report, 41, 783-787.

[15] Nettlemen, M.D. (1993) The Impact of Infection Control. In: Wenzel, R.P., Ed., Prevention and Control of Nosocomial Infections, 2nd Edition, Williams \& Wilkins, Baltimore.

[16] Abussaud, M.J.I. (1990) Prevalence of Nosocomial Infections in a Saudi Arabian Teaching Hospital. Journal of Hospital Infection, 17, 235-238. http://dx.doi.org/10.1016/0195-6701(91)90236-2

[17] Memish, Z., Djazmati, W., Cunningham, G. and Oni, G. (2000) The Incidence and Risk Factors of Ventilator Associated Pneumonia in a Riyadh Hospital. Infection Control and Hospital Epidemiology, 21, 271-273. http://dx.doi.org/10.1086/501758

[18] Mah, M., Pyper, A., Oni, G. and Memish, Z. (2001) Impact of Antibiotic Prophylaxis on Wound Infection after Cesarean Section in a Situation of Expected Higher Risk. American Journal of Infection Control, 29, 85-88. http://dx.doi.org/10.1067/mic.2001.111372

[19] Mah, M., Memish, Z., Cunningham, G., et al. (2001) An Outbreak of Acinetobacter baumannii in an ICU associated with tracheostomy. American Journal of Infection Control, 29, 284-288. http://dx.doi.org/10.1067/mic.2001.114232

[20] Embil, J., Almuneef, M., Nicoll, D., et al. (2001) MRSA: Profiles Oceans Apart, Contrasting a Canadian and Saudi Arabian Experience. Journal of Chemotherapy, 13, 28-33.

[21] Ronald, A. and Memish, Z. (2001) Infectious Diseases: Career Preparation. Journal of Chemotherapy, 13, 50-53.

[22] (2008) Core Components for Infection Prevention and Control Programmes: Report of the Second Meeting of the Informal Network on Infection Prevention and Control in Health Care. Geneva, 26-27 June 2008, WHO/HSE/EPR/ 2009.1. http://www.who.int/csr/resources/publications/WHO_HSE_EPR_2009_1/en/index.html

[23] Scheckler, W.E., Brimhall, D., Buck, A.S., Farr, B.M., Friedman, C., Garibaldi, R.A., et al. (1998) Requirements for Infrastructure and Essential Activities of Infection Control and Epidemiology in Hospitals: A Consensus Panel Report. Society for Healthcare Epidemiology of America. Infection Control and Hospital Epidemiology, 19, 114-124. http://dx.doi.org/10.2307/30142002

[24] Smith, P.W. and Rusnak, P.G. (1997) Infection Prevention and Control in the Long-Term-Care Facility. SHEA Long-Term-Care Committee and APIC Guidelines Committee. American Journal of Infection Control, 25, 488-512. http://dx.doi.org/10.1016/S0196-6553(97)90072-9

[25] Griffiths, P., Renz, A., Hughes, J. and Rafferty, A.M. (2009) Impact of Organisation and Management Factors on Infection Control in Hospitals: A Scoping Review. Journal of Hospital Infection, 73, 1-14. http://dx.doi.org/10.1016/j.jhin.2009.05.003

[26] Horan-Murphy, E., Barnard, B., Chenoweth, C., Friedman, C., Hazuka, B., Russell, B., et al. (1999) APIC/CHICACanada Infection Control and Epidemiology: Professional and Practice Standards. Association for Professionals in Infection Control and Epidemiology, Inc., and the Community and Hospital Infection Control Association-Canada. 
American Journal of Infection Control, 27, 47-51. http://dx.doi.org/10.1016/S0196-6553(99)70073-8

[27] Zoutman, D.E., Ford, B.D., Bryce, E., Gourdeau, M., Hebert, G., Henderson, E., et al. (2003) The State of Infection Surveillance and Control in Canadian Acute Care Hospitals. American Journal of Infection Control, 31, 266-272; Discussion 72-73. http://dx.doi.org/10.1067/mic.2003.88

[28] Plowman, R., Graves, N., Griffin, M.A., Roberts, J.A., Swan, A.V., Cookson, B., et al. (2001) The Rate and Cost of Hospital-Acquired Infections Occurring in Patients Admitted to Selected Specialties of a District General Hospital in England and the National Burden Imposed. Journal of Hospital Infection, 47, 198-209. 